\title{
Mapping the Hot Deformation Microstructure of Ni-30Fe Alloy
}

\author{
H. BELADI, P. D. HODGSON and M. R. BARNETT
}

School of Engineering and Technology, Deakin University, Geelong, Vic 3217 Australia. E-mail: hossein.beladi@deakin.edu.au, phodgson@deakin.edu.au, barnettm@deakin.edu.au.

(Received on March 9, 2005; accepted on August 11, 2005)

\begin{abstract}
The evolution of structure during the hot working of an austenitic Ni-30\%Fe alloy is studied using EBSD analysis of samples tested in torsion. A microstructural map in temperature-strain space that plots grain size, cell size, fracture and dynamic recrystallization is presented.
\end{abstract}

KEY WORDS: microstructural map; hot deformation; hot torsion; Ni-30Fe alloy.

\section{Introduction}

The hot deformation of metals can entail a wide range of process conditions, from creep through to high rate forming. Ashby and coworkers were among the first to introduce hot working mechanism maps for a wide range of metals in the 1980's. ${ }^{1}$ Their work focused mainly on creep conditions, although there was a limited approach into the hot working range. These maps were based on the relationships between three variables: stress, temperature and strain rate. From an industrial thermomechanical perspective, the effect of strain and the state of the microstructure are of considerable interest. The present work is concerned with the construction of microstructural maps in strain-temperature space for hot deformation conditions of interest to industry. As maps of this general nature have been used by others $^{2,3)}$ we aim to show their usefulness in conveying a wide range of information about hot deformation.

Steel is the most widely thermomechanically processed metal. However, the transformation of austenite during cooling has made it difficult to study the evolution of microstructure during hot deformation. Recently, model alloys (e.g. $\mathrm{Ni}-30 \% \mathrm{Fe}$ ) have been used to study the austenite behaviour at high temperature. ${ }^{4)}$ The model alloy retains a stable austenitic structure after cooling to room temperature, allowing the high temperature deformation microstructures to be readily characterized. In addition, the stacking fault energy of this alloy is similar to pure iron and austenite in low carbon steels. ${ }^{5)}$ The aim of the current study is to develop a microstructural map for hot worked $\mathrm{Ni}-30 \% \mathrm{Fe}$.

\section{Experimental Procedure}

The composition of the alloy used in this study was $\mathrm{Ni}-29.5 \mathrm{Fe}-0.01 \mathrm{C}-0.02 \mathrm{Mn}$ (in $\mathrm{wt} \%$ ). An as-received billet was reduced in thickness by hot rolling to $20 \mathrm{~mm}$ at temperatures between 1200 and $1000^{\circ} \mathrm{C}$. Torsion samples with a gauge length of 20 and $6.7 \mathrm{~mm}$ in diameter were machined out of the $20 \mathrm{~mm}$ plate with the longitudinal axis parallel to the rolling direction. The hot torsion machine, which has described in detail elsewhere, ${ }^{6}$ allows a wide range of thermomechanical processing conditions to be simulated.

During testing, the entire length of the specimen was enclosed in a quartz glass tube, in which a positive pressure of argon was maintained to prevent oxidation of specimen. Two holes were drilled along the axis of each specimen through the shoulder to the start of the gauge length to allow an $\mathrm{N}$ type thermocouple to be inserted into each end of the specimen during testing to measure the temperature at the edge of the gauge length. The maximum temperature difference between the two ends was $10^{\circ} \mathrm{C}$. Equivalent true stress-true strain values were calculated from the torquetwist data using the method based on the analysis by Fields and Backofen. ${ }^{7)}$

Hot torsion experiments were conducted over a temperature range of 700 and $1000^{\circ} \mathrm{C}$ to strains of 1 and/or the fracture strain at a strain rate of $1 \mathrm{~s}^{-1}$. The samples were water quenched immediately (i.e. $<0.5 \mathrm{~s}$ ) after deformation. Microstructural characterization was performed on tangential sections at a depth of $\sim 100 \mu \mathrm{m}$ below the surface of the gauge length. Samples for the electron backscattered diffraction (EBSD) were prepared by mechanical polishing finished with a Colloidal Silica slurry polish. EBSD was employed to measure size and volume fraction of recrystallized grains as well as the misorientation angles between adjacent grains. Mean recrystallized grain size was measured through the linear intercept method with EBSD being used to distinguish the grain boundaries with misorientation angles more than $15^{\circ}$ using HKL Technology Channel 5. EBSD images were constructed either using a step size of $0.05 \mu \mathrm{m}$ for characterization of intragranular defects or $0.7 \mu \mathrm{m}$ to study the overall microstructure (i.e. $\sim 20$ grains). Backscattered imaging was also used to reveal the intragranular defect structure.

\section{Results and Discussion}

The initial microstructure of the alloy prior to deformation consisted of coarse statically recrystallized grains $(\sim 110 \mu \mathrm{m}$ mean diameter) containing a large quantity of 
annealing twins. The stress-strain curves showed a clear peak for different deformation temperatures (Fig. 1(a)). They all displayed a region of power law type work hardening followed by work softening to a steady state stress for deformation temperatures above $800^{\circ} \mathrm{C}$. This type of behaviour is indicative of dynamic recrystallization (DRX). At lower temperatures adiabatic heating during deformation and early fracture complicates the analysis.

Figure 1(b), for example, shows a schematic stress-strain curve for a metal undergoing DRX. Three critical strains are identified. The critical strain for the onset of DRX $\left(\varepsilon_{\mathrm{C}}\right)$ is determined here through inspection of the second differential of stress with strain according to the technique discussed in Ref. 8). Beyond the strain of the peak stress $\left(\varepsilon_{\mathrm{p}}\right)$ the stress is reduced by DRX and reaches a steady-state stress level at which the work hardening and work softening are balanced. The onset of this condition is termed the steady state strain $\left(\varepsilon_{\mathrm{SS}}\right)$. The curve could be, therefore, classified into three regions; work hardening, partial DRX and

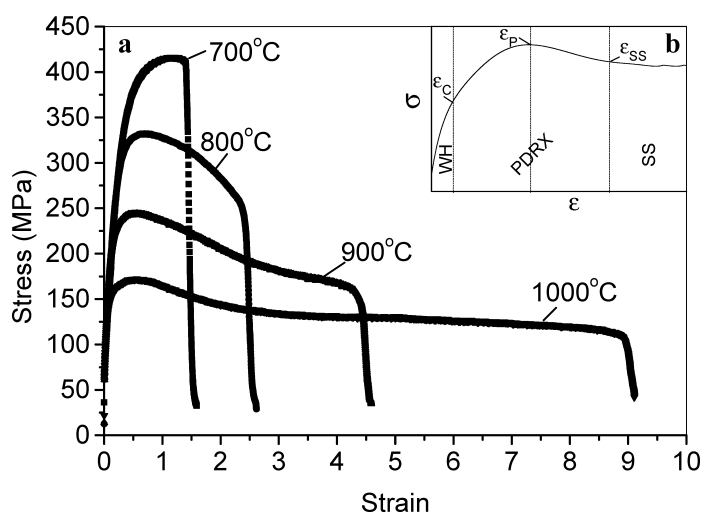

Fig. 1. (a) The stress-strain curves of alloy at different deformation temperatures at strain rate of $1 \mathrm{~s}^{-1}$. (b) Schematic representation of a hot deformation curve undergoing dynamic recrystallization. WH, PDRX and SS are work hardening, partial dynamic recrystallization and steady state, respectively. steady state (Fig. 1(b)).

These three characteristic strains $\left(\varepsilon_{\mathrm{C}}, \varepsilon_{\mathrm{P}}, \varepsilon_{\mathrm{SS}}\right)$ were determined for different thermomechanical conditions and plotted in a strain-temperature map in Fig. 2. Four regions are shown; I, work hardening; III, partial DRX; IV, steady state DRX; V, fracture (region II was termed dynamic recovery steady state region in a previous publication, ${ }^{9)}$ a similar classification was therefore applied in this study to keep the consistency). The strains for $\varepsilon_{\mathrm{C}}, \varepsilon_{\mathrm{P}}$ and $\varepsilon_{\mathrm{SS}}$ increased with a decrease in the deformation temperature from 1000 to $700^{\circ} \mathrm{C}$. However, the ductility $\left(\varepsilon_{\mathrm{F}}\right)$ was significantly reduced with a decrease in deformation temperature (Fig. 2). These give the basic boundaries in the map to represent the most important dynamic microstructure changes in austenite.

A strain of 1 was chosen to quantify the deformed structures at different deformation temperatures (this value is beyond $\varepsilon_{\mathrm{C}}$ for all deformation temperatures and therefore allows the formation of substructure and its relationship to DRX to be studied). The as-quenched microstructures revealed that the deformation temperature has a strong effect on evolution of structure. The pre-existing boundaries were

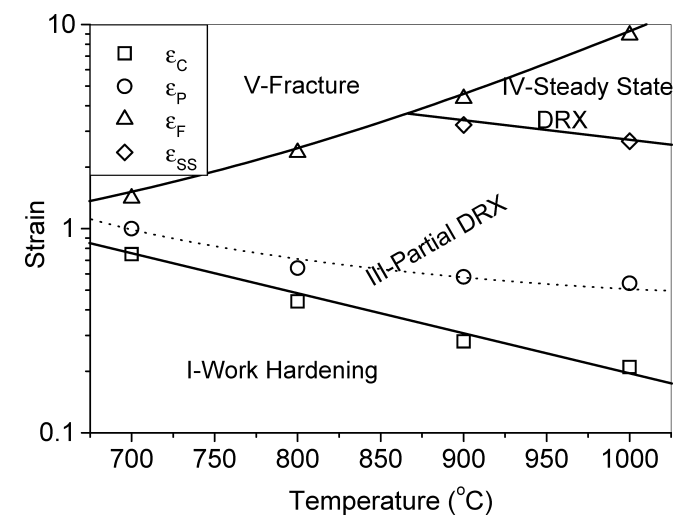

Fig. 2. Hot deformation map of $\mathrm{Ni}-30 \mathrm{Fe}$ based on mechanical behaviour of alloy at strain rate of $1 \mathrm{~s}^{-1}$.
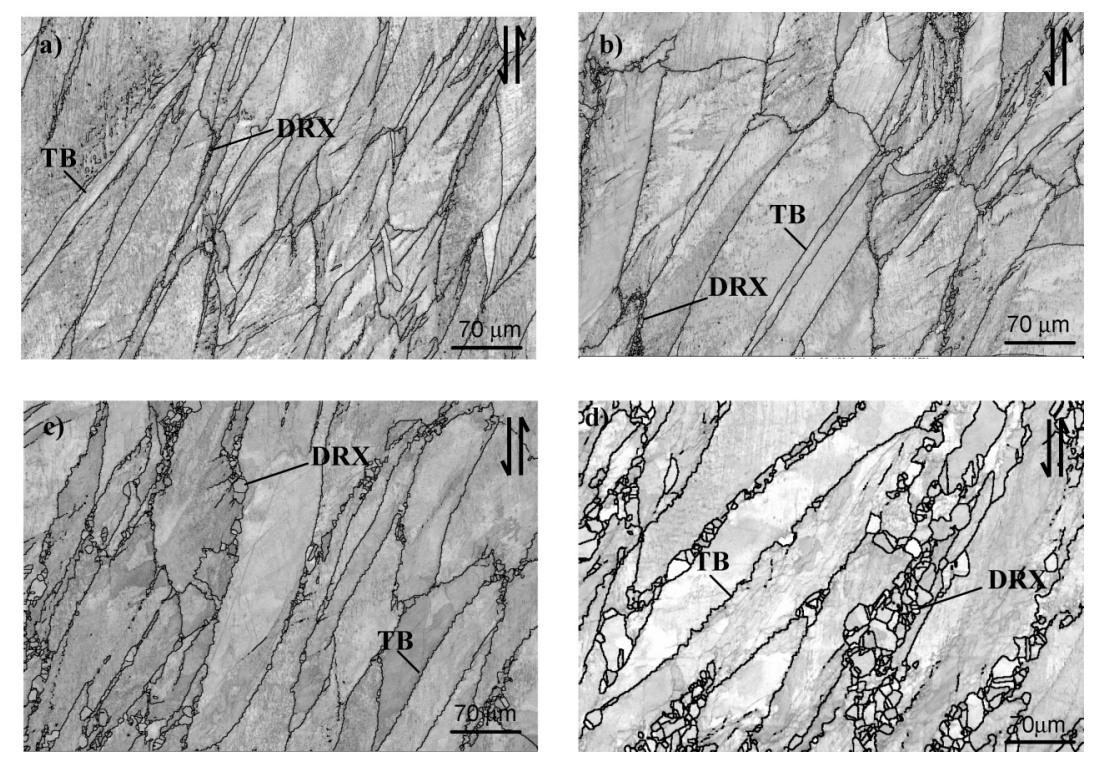

Fig. 3. As-quenched microstructures at strain of 1 and strain rate of $1 \mathrm{~s}^{-1}$ for different deformation temperatures: (a) $700^{\circ} \mathrm{C}$, (b) $800^{\circ} \mathrm{C}$, (c) $900^{\circ} \mathrm{C}$ and (d) $1000^{\circ} \mathrm{C}$. TB and DRX are twin boundaries and dynamic recrystallized grains, respectively. Parallel arrows indicate the deformation direction. 
serrated and the serration amplitude increased with an increase in the deformation temperature. The serration of twin boundaries was much less compared with the grain boundaries and mainly observed above a deformation temperature of $900^{\circ} \mathrm{C}$ (Fig. 3). This could be explained due to very low mobility of twin boundaries in FCC materials. The boundary serrations can play a key role in the microstructural evolution as the bulged area surrounded by the serration can act as a nucleus for recrystallization. ${ }^{10)}$ Suh et $a l .{ }^{2)}$ showed that the boundary serration is temperature dependent and believed that the interaction between boundaries and sub-boundaries is responsible for the development of the serrations.

The new recrystallized grains mainly formed on pre-existing grain boundaries during deformation (Fig. 3), as is commonly observed for DRX. ${ }^{10)}$ The volume fraction of recrystallized grains and their sizes increased with an increase in the deformation temperature which is consistent with the data for the $\mathrm{Ni}-30 \mathrm{Fe}$ alloy by Suh et al. ${ }^{11)}$ (Fig. 3 and Fig. 4). This comparison also illustrated that the recrystallized grain size decreased with an increase in the strain rate (Fig. 4).

The backscattered electron imaging revealed extensive parallel band-like structures within individual austenite grains throughout the microstructure for all deformation temperatures (Fig. 5(a)). These bands have been termed microbands $^{12)}$ and are bounded by geometrically necessary boundaries. $^{13)}$ The misorientation angle across the mi- croband boundaries (Fig. 5(b)) varies with deformation temperature and strain.

Inspection of the misorientation angles across the microband boundaries showed that they increased with strains for a given deformation temperature, as reported by other groups. ${ }^{4,12,14)}$ The deformation temperature also had a strong effect on the microband characteristics, with an increase in refinement and overall misorientation angle for a decrease in deformation temperature. A similar result was reported by Adachi and Hinotani. ${ }^{15)}$

To gain an impression of the evolution of the substructure, the average intercept length between boundaries with a

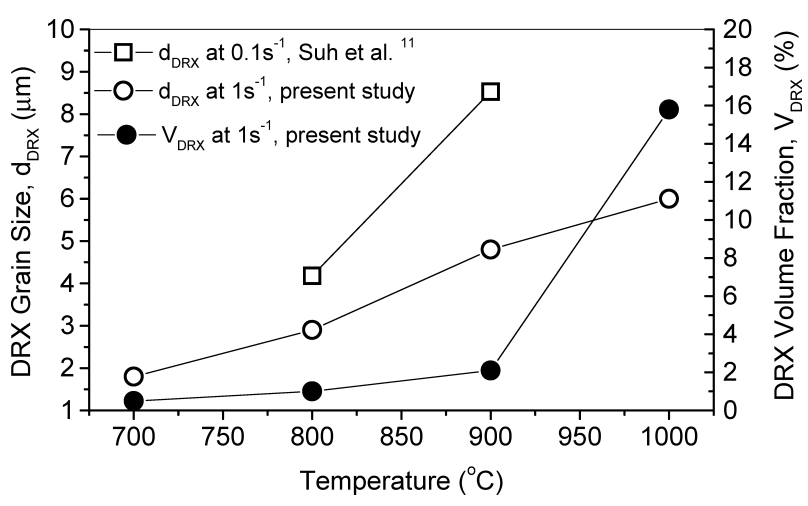

Fig. 4. Grain size and volume fraction of dynamic recrystallized grains as a function of deformation temperature at different strain rates.
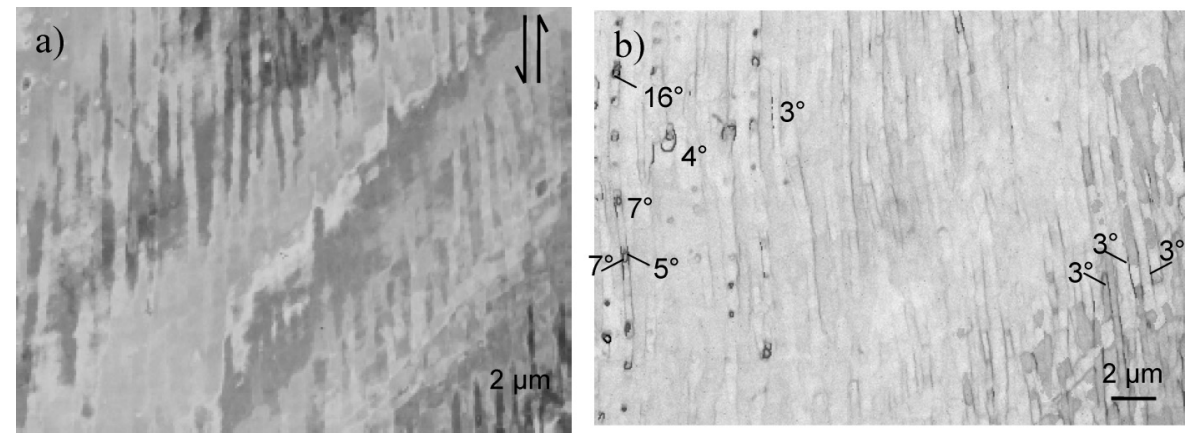

Fig. 5. Deformed structure of a grain interior at temperature of $800^{\circ} \mathrm{C}$, strain of 1 and strain rate of $1 \mathrm{~s}^{-1}$; (a) backscattered image and (b) EBSD image of area (a). Parallel arrows indicate the deformation direction and numbers show the misorientation angles across microbands.

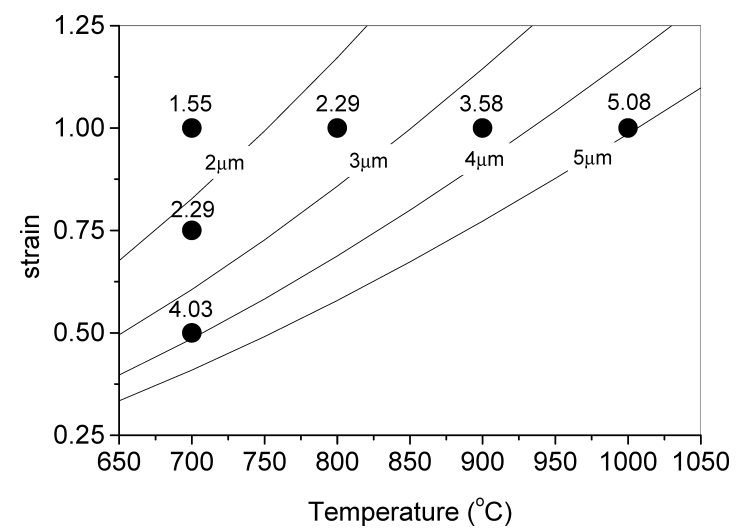

Fig. 6. Influence of strain and deformation temperature on the average linear intercept between boundaries with a misorientation greater than $1.5^{\circ}$. Lines fitted according to empirical fit, $l_{1.5}=200 \varepsilon^{-1.3} \exp (-4700 / \mathrm{T})$.

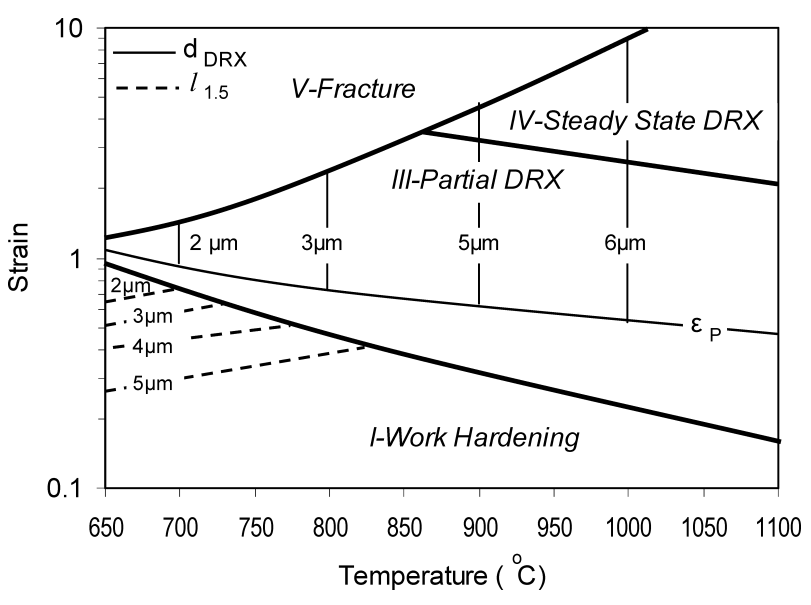

Fig. 7. Microstructural map of austenite during hot deformation at a strain rate of $1 \mathrm{~s}^{-1}$. 
misorientation greater than $1.5^{\circ}, l_{1.5}$ (a value that reflects the effective limit of the technique and which approximates the subgrain size) was measured (Fig. 6). The values for $l_{1.5}$ significantly reduced with a decrease in the deformation temperature. A similar trend was seen with an increase in the strain. This is as expected and contours of constant $l_{1.5}$ are approximated from the data in Fig. 6.

By combining the information in Figs. 2, 3 and 5, it is possible to develop a microstructural map that summarizes the grain size and microband spacing (Fig. 7). The average cell/subgrain size is an important parameter in region I (i.e. dashed lines) where the subgrain was refined with an increase in the strain and a decrease in deformation temperature. It is worth mentioning that this behaviour of subgrain changes is also seen beyond $\varepsilon_{\mathrm{C}}$ (i.e. region III).

It has been reported that the recrystallized grain size reaches a characteristic value, depending on the thermomechanical condition, after a small fraction of recrystallization ${ }^{16)}$ In regions III and IV, it was, therefore, assumed that the DRX grain size is independent of strain at a given deformation temperature; however the lines of constant DRX grain size are not extended to the $\varepsilon_{\mathrm{C}}$ curve because the DRX grain size was not determined at the onset of DRX in this study. In region III, dynamic recrystallization is the dominant softening mechanism. The DRX grains were refined with a decrease in the deformation temperature. The region IV shows a condition in which the metadynamic recrystallization takes place and the level of stress does not change with the strain.

It is worth mentioning that the initial grain size has a strong effect on both the mechanical behaviour of the stress-strain curve and the microstructural characteristics. Therefore, this will change the extent of each region in the map. For the microstructural map to be practical in industry, the effect of strain rate must also be considered. In this case a map in strain- $Z$ space ( $Z$ is Zener-Hollomon parameter) would be more suitable. More experiments are planned to extend the existing strain-temperature map to a strain- $Z$ map and to consider the effect of initial grain size.

\section{Summary}

A Ni-30wt $\% \mathrm{Fe}$ was used to study the austenite structure evolution during hot working. The deformed structures were examined at different thermomechanical conditions using the EBSD technique. The results were summarized in a microstructural map.

\section{Acknowledgements}

The authors acknowledge the Australian Research Council who supported this work. The authors are grateful to NEDO, Japan, the Ferrous Nano Metal Project and Professor Setsuo Takaki, Kushu University, Japan, for supply of the Ni-30Fe model alloy.

\section{REFERENCES}

1) H. J. Frost and M. F. Ashby: Deformation-Mechanism Maps, First Ed., Pergamon Press, England, (1982), 1.

2) D. W. Suh, T. Inoue, S. Torizuka, A. Ohmori and K. Nagai: ISIJ Int., 42 (2002), 1026.

3) A. I. Fernandez, P. Uranga, B. Lopez and J. M. Rodriguez-Ibabe: Mater. Sci. Eng. A, A361 (2003), 367.

4) P. J. Hurley: PhD thesis, Monash University, Melbourne, Australia, (2000).

5) W. Charnock and J. Nutting: Metal Sci. J., 1 (1967), 123.

6) P. D. Hodgson, D. C. Collinson and B. Perrett: Proc. of the Int. Symp. on Physical Simulation, NRIM, Tsukuba, (1997), 219.

7) D. S. Fields and W. A. Backofen: Proc. Amer. Soc. Test. and Mater., 75 (1957), 1259.

8) E. I. Poliak and J. J. Jonas: ISIJ Int., 43 (2003), 684.

9) M. R. Barnett: Mater. Sci. Forum, 426-432 (2003), 515.

10) F. J. Humphreys and M. Hatherly: Recrystallization and Related Annealing Phenomena, Pergamon, Oxford, (1995), 206.

11) D-W. Suh, S. Torizuka, A. Ohmori, T. Inoue and K. Nagai: ISIJ Int., 42 (2002), 432.

12) D. A. Hughes and W. D. Nix: Mater. Sci. Eng. A, A122 (1989), 153.

13) N. Hansen: Metall. Mater. Trans. A, 32A (2001), 2917.

14) J. Y. Cho, T. Inoue, F. Yin and K. Nagai: Mater. Trans., 45 (2004), 2966.

15) Y. Adachi and S. Hinotani: Inter. Symp. on Ultrafine Grained Steels, ISIJ, Tokyo, (2001), 84.

16) P. J. Sah, C. J. Richardson and C. M. Sellars: Met. Sci., 8 (1974), 325. 